\title{
Non-Malignant Neoplasm
}

National Cancer Institute

\section{Source}

National Cancer Institute. Non-Malignant Neoplasm. NCI Thesaurus. Code C163003.

A category that includes benign neoplasms and neoplasms with uncertain malignant potential. The latter are characterized by clinicopathological features that are not benign, including some degree of mild or mild/moderate atypia/dysplasia, but lack overt malignant morphologic characteristics and there is no evidence of metastasis at the time of diagnosis. 